\title{
TÉCNICAS PARA A OBTENÇÃO DE PREPARAÇÕES CITOLÓGICAS COM ALTA FREQÜÊNCIA DE METÁFASES MITÓTICAS EM PLANTAS: PASSIFLORA (PASSIFLORACEAE) E CROTALARIA (LEGUMINOSAE) ${ }^{1}$
}

\author{
Silvia Marina $\mathrm{Cuco}^{2}$ \\ Mateus Mondin² \\ Maria Lúcia Carneiro Vieira ${ }^{2}$ \\ Margarida L. R. Aguiar-Perecin ${ }^{2,3}$
}

Recebido em 15/01/2001. Aceito em 12/12/2002

\begin{abstract}
RESUMO - (Técnicas para a obtenção de preparações citológicas com alta freqüência de metáfases mitóticas em plantas: Passiflora (Passifloraceae) e Crotalaria (Leguminosae)). Foram conduzidos experimentos visando à otimização de procedimentos para preparações citológicas de pontas de raiz com alta freqüência de metáfases mitóticas, apresentando cromossomos com morfologia nítida, em espécies pertencentes a dois gêneros de plantas, Passiflora (Passifloraceae) e Crotalaria (Leguminosae). Para o acúmulo de metáfases, bem como de prófases e prometáfases com cromossomos bem condensados, foram avaliados pré-tratamentos de raízes, em que foram utilizadas diferentes combinações de 8-hidroxiquinolina, inibidor do fuso mitótico, com cicloheximida, inibidor da síntese protéica. As preparações foram coradas pelo método de Feulgen. Os melhores resultados foram obtidos com o tratamento com 8-hidroxiquinolina a 300ppm combinado com cicloheximida a 3,125ppm, por 1 hora e 30 minutos para as espécies de Passiflora, e a combinação de 8-hidroxiquinolina a 300ppm + cicloheximida a 6,25ppm também durante 1 hora e 30 minutos para as espécies de Crotalaria. Esta investigação ilustra a situação de dois gêneros de plantas em que a adequação de pré-tratamentos diferiu entre os grupos, e é fundamental para estudos envolvendo comparação do cariótipo das espécies, sobretudo para a detecção de marcadores cromossômicos evidenciados por meio de métodos diversos de citogenética (bandamento- $\mathrm{C}$, bandamento com fluorocromos $\mathrm{e}$ hibridação in situ fluorescente).
\end{abstract}

Palavras-chave - Passiflora, Crotalaria, citogenética vegetal, cromossomos mitóticos, 8-hidroxiquinolina, cicloheximida

\begin{abstract}
Techniques to obtain cytological preparations with high frequency of mitotic metaphases in plants: Passiflora (Passifloraceae) and Crotalaria (Leguminosae)). Experiments were carried out aiming to optimize procedures for cytological preparations of root tips with high frequency of metaphase cells showing clear features of chromosome morphology, in species belonging to two genera of plants, Passiflora (Passifloraceae) and Crotalaria

1 Parte da Tese de Doutorado do segundo Autor

2 Departamento de Genética, Escola Superior de Agricultura "Luiz de Queiroz", Universidade de São Paulo, C. Postal 83, CEP 13400-970, Piracicaba, SP, Brasil

3 Autor para correspondência: mlrapere@carpa.ciagri.usp.br
\end{abstract}


(Leguminosae). For the accumulation of metaphases, as well as prophases and prometaphases with well condensed chromosomes, pretreatments of root tips with different combinations of 8-hydroxiquinoline, a mitotic fuse inhibitor and with cycloheximide, a protein synthesis inhibitor, were evaluated in Feulgen stained preparations. The treatments with 8 -hydroxiquinoline at $300 \mathrm{ppm}+$ cycloheximide at $3.125 \mathrm{ppm}$, and with 8 -hydroxiquinoline at $300 \mathrm{ppm}+$ cycloheximide at $6.25 \mathrm{ppm}$, both for 1 hour and 30 minutes, were more effective respectively for Passiflora and Crotalaria species. This investigation illustrates a case of differences of pretreatment procedures between two genera of plants, as well as represents a basic work for studies involving the comparison of the karyotype of species belonging to these genera, and especially, for the detection of chromosome markers via several cytogenetic methods (C-banding, fluorescent-chromosome banding and in situ hybridization).

Key words - Passiflora, Crotalaria, plant cytogenetics, mitotic chromosomes, 8-hydroxiquinoline, cycloheximide

\section{Introdução}

Os procedimentos para preparações citológicas com alta freqüência de metáfases para a análise de cariótipos de plantas dependem do estabelecimento de uma rotina de obtenção de raízes apresentando meristemas com alto índice mitótico. Normalmente, sementes recémgerminadas são a melhor fonte de tais raízes, mas em casos de espécies que produzem sementes muito pequenas ou de difícil germinação, outros métodos de indução de raízes devem ser explorados, tais como enraizamento de estacas em vasos ou em meio de cultura. Outro aspecto altamente desejável é a obtenção de preparações com alta freqüência de metáfases apresentando cromossomos com morfologia nítida. Vários pré-tratamentos para acúmulo de metáfases têm sido descritos em plantas, tais como a combinação de agentes inibidores do fuso mitótico e da síntese protéica, bem como o emprego de hidroxiuréia para sincronização das células meristemáticas (Tlaskal 1980; Pan et al. 1993; Schubert et al. 1993; Schwarzacher et al. 1994; Silvarolla \& Aguiar-Perecin 1994; Lee et al. 1996; Bertão \& Aguiar-Perecin, 2002).

No presente trabalho, são relatados os resultados de experimentos conduzidos para a obtenção de preparações citológicas de ponta de raiz com alta freqüência de metáfases mitóticas, dentro de um programa de pesquisa visando o mapeamento de marcadores cromossômicos (via métodos de bandamento e de hibridação molecular in situ) em espécies pertencentes aos gêneros Passiflora (Passifloraceae) e Crotalaria (Leguminosae).

O gênero Crotalaria, pertencente à subfamília Papilionoideae, é constituído de aproximadamente 600 espécies, distribuídas principalmente nos trópicos, ocupando regiões de vegetação tipo savana ou cerrado (Polhill 1982). Embora tenha um grande número de espécies, algumas das quais importantes para a agricultura, a análise citogenética do gênero restringiu-se apenas à contagem do número de cromossomos em poucas espécies (Gupta \& Gupta 1978; Raina \& Verma 1979) e à descrição do cariótipo de algumas delas (Palomino \& Vázquez 1991; Oliveira \& Aguiar-Perecin 1999). Nestes estudos, as raízes foram obtidas a partir de sementes recém-germinadas, ou de plântulas crescendo em vermiculita como substrato e pré-tratadas apenas com hidroxiquinolina.

O gênero Passiflora possui 465 espécies descritas (Vanderplank 1996), sendo algumas cultivadas devido às propriedades ornamentais, nutricionais ou medicinais. $\mathrm{O}$ gênero é pouco estudado citologicamente e os trabalhos têm se limitado à contagem do número de cromossomos (Killip 1938; Storey, 1950; Snow e MacDougal 1993; De Melo et al. 2001).

Para o acúmulo de metáfases e prometáfases foram avaliados vários pré-tratamentos em que se utilizaram não somente hidroxiquinolina, inibidor do fuso mitótico, mas também combinações da mesma com cicloheximida, inibidor da síntese protéica. Com o emprego 
desses pré-tratamentos visou-se selecionar células com cromossomos pouco condensados em que pudessem ser melhor visualizados os marcadores cromossômicos a serem analisados por outras técnicas.

\section{Material e métodos}

Foram estudadas duas espécies de Passiflora ( $P$. edulis f. flavicarpa e P. amesthystina), da família Passifloraceae, uma espécie diplóide de Crotalaria (C. juncea) e uma poliplóide (C. stipularia), da família Leguminosae. A Tab. 1 mostra os materiais analisados e os respectivos números de cromossomos relatados na literatura (Raina \& Verma 1979; Dornelas et al. 1995; Barbosa \& Vieira 1997; Oliveira \& Aguiar-Perecin 1999).
Sementes previamente escarificadas de Crotalaria foram germinadas em recipiente contendo Sphagnum umedecido, em sala climatizada a $28^{\circ} \mathrm{C}$. Ao atingirem tamanho aproximado de $1 \mathrm{~cm}$, as raízes foram cortadas $\mathrm{e}$ submetidas ao pré-tratamento com 8-hidroxiquinolina a $300 \mathrm{ppm}$ ou com combinações desta droga com diversas concentrações de cicloheximida, durante períodos de tempo variáveis (Tab. 1). Em seguida, as raízes foram transferidas para fixador de Carnoy (etanol:ácido acético 3:1), onde permaneceram por 12 horas à temperatura ambiente e posteriormente $\mathrm{a} 4^{\circ} \mathrm{C}$, até o momento de preparação das lâminas.

No caso de Passiflora, a obtenção de grande número de raízes para a rotina de trabalho foi mais eficiente a partir do cultivo de estacas de plantas matrizes, desenvolvido em telado. As

Tabela 1. Espécies de Passiflora (Passifloraceae) e Crotalaria (Leguminosae), respectivos números de cromossomos e pré-tratamentos utilizados.

P. edulis Sims. f. flavicarpa Deg. $(2 \mathrm{n}=2 \mathrm{x}=18)^{*}$

$P$. amethystina Mikan $(2 \mathrm{n}=2 \mathrm{x}=18)^{*}$

Hidroxiquinolina a $300 \mathrm{ppm}$

Hidroxiquinolina a 300ppm

Hidroxiquinolina a 300ppm

Hidroxiquinolina a $300 \mathrm{ppm}+$ Cicloheximida a $6,25 \mathrm{ppm}$

Hidroxiquinolina a $300 \mathrm{ppm}+$ Cicloheximida a $6,25 \mathrm{ppm}$

Hidroxiquinolina a 300ppm + Cicloheximida a $3,125 \mathrm{ppm}$

Hidroxiquinolina a 300ppm + Cicloheximida a $3,125 \mathrm{ppm}$

Hidroxiquinolina a 300ppm + Cicloheximida a $3,125 \mathrm{ppm}$

C. juncea L. $(2 \mathrm{n}=2 \mathrm{x}=16)^{* *}$

Hidroxiquinolina a 300ppm

Hidroxiquinolina a $300 \mathrm{ppm}+$ Cicloheximida a $12,5 \mathrm{ppm}$

Hidroxiquinolina a $300 \mathrm{ppm}+$ Cicloheximida a $12,5 \mathrm{ppm}$

Hidroxiquinolina a 300ppm + Cicloheximida a $3,125 \mathrm{ppm}$

C. stipularia Desv. $(2 \mathrm{n}=4 \mathrm{x}=32)^{* *}$

Hidroxiquinolina a $300 \mathrm{ppm}+$ Cicloheximida a $6,25 \mathrm{ppm}$

Hidroxiquinolina a $300 \mathrm{ppm}+$ Cicloheximida a $6,25 \mathrm{ppm}$

* Número de cromossomos de acordo com Barbosa \& Vieira (1997) e De Melo et al. (2001).

** Número de cromossomos de acordo com Raina \& Verma (1979) e Oliveira \& Aguiar-Perecin (1999). 
estacas foram cultivadas em copos de plástico contendo o substrato Plantmax composto de vermiculita, turfa e cascas vegetais processadas e, após 15 a 20 dias, as primeiras raízes emergentes foram coletadas. Os pré-tratamentos utilizando 8-hidroxiquinolina e combinações com cicloheximida estão apresentados na Tab. 1.

Para a avaliação dos efeitos dos prétratamentos, as raízes foram coradas pelo método de Feulgen, de acordo com AguiarPerecin \& Vosa (1985), com algumas modificações. As raízes fixadas de Passiflora e Crotalaria foram hidrolisadas em $\mathrm{HCl} 1 \mathrm{~N}$ a $60^{\circ} \mathrm{C}$ durante 12 e 8 minutos, respectivamente, lavadas em água destilada e coradas em reativo de Schiff por 45 minutos. Procedeu-se à nova lavagem em água destilada, seguida de maceração em solução enzimática composta de celulase a $2 \%$ e pectinase a $3 \%$, a $37^{\circ} \mathrm{C}$, durante 13 e 30 minutos, respectivamente, para Passiflora e Crotalaria. Após lavagem em tampão citrato (ácido cítrico $4 \mathrm{mM}+$ citrato trisódico $6 \mathrm{mM}$ ), as pontas das raízes foram esmagadas em carmin acético a $1 \%$. As lamínulas foram removidas em nitrogênio líquido ou ácido acético a $45 \%$ e as lâminas então montadas em bálsamo do Canadá. As fotomicrografias dos cromossomos de Passiflora e de Crotalaria foram feitas em microscópio Axiophot 2 (Zeiss), utilizando-se o filme Kodak Technical Pan ISO 25 (Kodak).

\section{Resultados e discussão}

Passiflora - Os pré-tratamentos descritos resultaram em acúmulo de metáfases, e as melhores preparações, com cromossomos bem espalhados, apresentando morfologia nítida, foram obtidas com a combinação de 8-hidroxiquinolina a $300 \mathrm{ppm}$ com cicloheximida a $3,125 \mathrm{ppm}$ por 1 hora e 30 minutos. A Fig. 1 mostra o aspecto geral de preparações feitas a partir de pontas de raiz de P. edulis f. flavicarpa submetidas a este pré-tratamento. Preparações das duas espécies de Passiflora mostraram o mesmo tipo de resposta a este tratamento, ou seja, grande número de metáfases com os cromossomos com grau de condensação adequado para análise de sua morfologia. As Figs. 2 e 3 apresentam metáfases de $P$. edulis f. flavicarpa e $P$. amethystina onde se observam os cromossomos bem condensados e espalhados, visualizando-se claramente a presença de constrições secundárias e satélites nos pares de cromossomos 8 e 9 , os menores do cariótipo dessas espécies. Nas preparações de raízes tratadas apenas com 8-hidroxiquinolina, observou-se menor número de metáfases com os cromossomos bem condensados, geralmente apresentando maior grau de sobreposição. Os tratamentos com duração maior que 1 hora e 30 minutos ou utilizando dose mais elevada de cicloheximida $(6,25 \mathrm{ppm})$ resultaram em alta contração dos cromossomos, o que dificulta sua análise morfológica.

Esses resultados foram importantes para o estabelecimento de uma rotina para a preparação de metáfases e prófases com cromossomos bem condensados, visando a analise de regiões organizadoras do nucléolo em experimentos de hibridização molecular fluorescente in situ, cujos resultados serão apresentados em outra publicação.

O efeito da 8-hidroxiquinolina e da cicloheximida tem sido explorado em diferentes espécies de plantas e o uso de concentrações e tempos de tratamento adequados é importante não somente para o acúmulo de metáfases, como também de prófases finais e prometáfases com cromossomos condensados, que também podem ser utilizadas para a análise de cariótipos. A superioridade do tratamento combinado das duas drogas pode ser compreendida de acordo com noções postuladas por Tlaskal (1980): a cicloheximida entra rapidamente nas células meristemáticas e inibe a mitose, impedindo o escape da metáfase para as fases subseqüentes; a cicloheximida causa supercontração dos cromossomos nas fases de prófase e metáfase; 

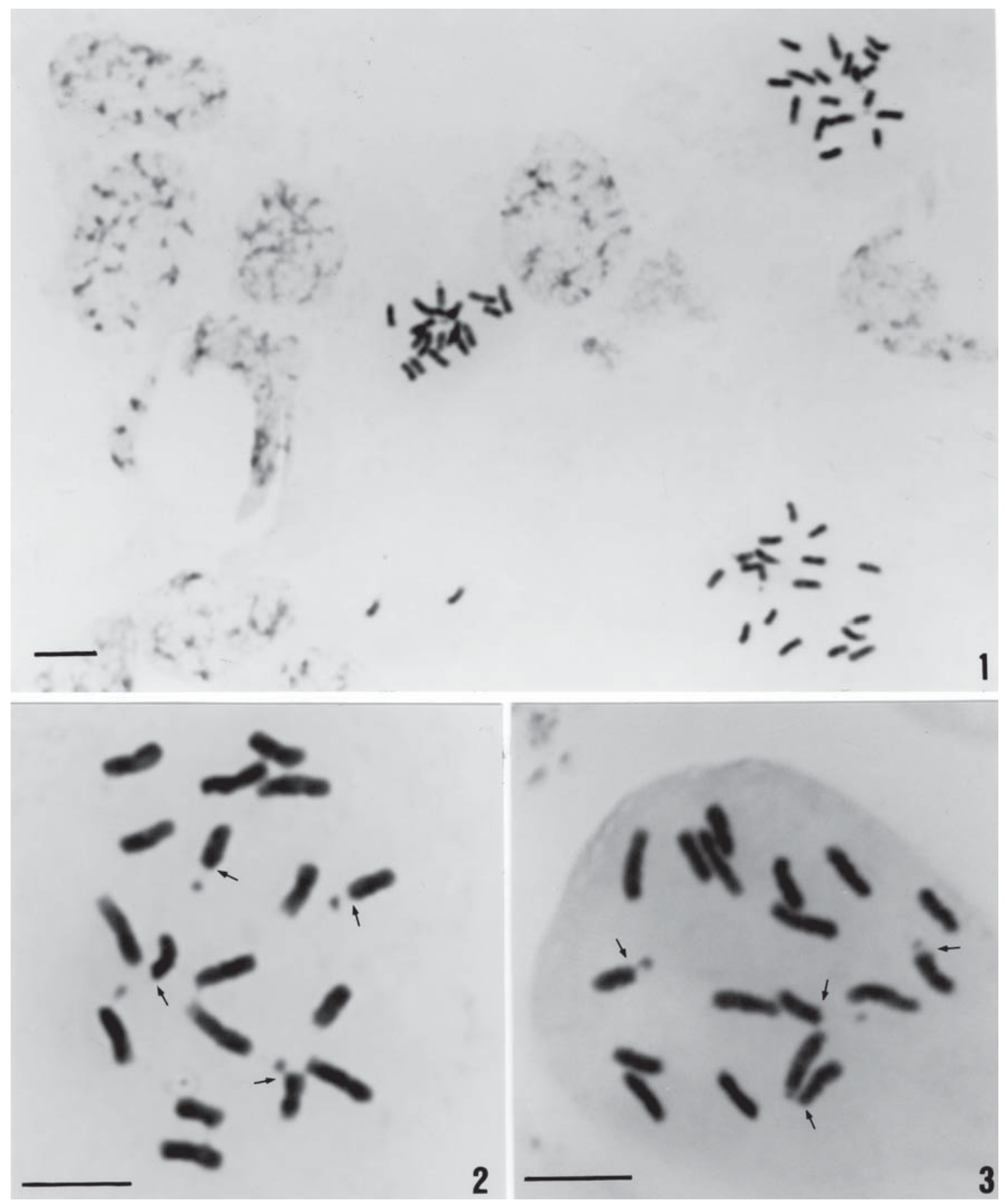

Figuras 1-3. 1. Acúmulo de células metafásicas em meristema radicular de Passiflora edulis f. flavicarpa após tratamento com 8-hidroquinolina a 300ppm + cicloheximida a 3,125ppm por 1 hora e 30 minutos, e coloração pelo método de Feulgen. 2-3. Metáfases de Passiflora edulis e Passiflora amethystina, respectivamente, com $2 \mathrm{n}=18$ cromossomos, apresentando dois pares de cromossomos com constrição secundária e satélite (setas). Barras de escala $=5 \mu \mathrm{m}$. 
a hidroxiquinolina quando entra na célula já afetada pela cicloheximida inibe o fuso mitótico e permite o espalhamento dos cromossomos durante o esmagamento; a 8-hidroxiquinolina contrai apenas os cromossomos metafásicos.

Crotalaria - Os pré-tratamentos de raízes avaliados entre as espécies de Crotalaria (Tab. 1) resultaram em acúmulo de metáfases, mas foi a combinação de 8-hidroxiquinolina a $300 \mathrm{ppm}+$ cicloheximida a $6,25 \mathrm{ppm}$, com duração de 1 hora e 30 minutos, a que induziu maior freqüência de metáfases apresentando cromossomos com morfologia nítida, como se vê na Fig. 4, que ilustra uma preparação de raiz de $C$. juncea submetida a este pré-tratmento. Em trabalho anterior (Oliveira \& Aguiar-Perecin, 1999), foi feita a análise do cariótipo de várias espécies de Crotalaria, a partir da observação de metáfases pré-tratadas com 8-hidroxiquinolina $0,002 \mathrm{M}$ por 4 horas e coradas pelo método de Feulgen, apresentando cromossomos com o mesmo grau de condensação e morfologia nítida, e em que a maioria das espécies apresentou uma constrição secundária no braço curto do cromossomo 1 . No presente trabalho, o pré-tratamento acima mencionado permitiu não somente o acúmulo de metáfases onde se vê claramente a posição do centrômero e da constrição secundária (Fig. 5), como também de prometáfases (Fig. 6) e prófases finais com cromossomos bem condensados e com morfologia nítida. Na Fig. 6, pode-se observar um dos cromossomos do par número $1 \mathrm{com}$ a constrição secundária muito distendida, aspecto este muito característico de prometáfases e prófases. As prometáfases podem ser distinguidas das metáfases pela presença das extremidades um pouco descondensadas, e as prófases com cromossomos condensados pela ação da cicloheximida, pela visualização do contorno do envoltório nuclear.

O tratamento com a combinação de 8-hidroxiquinolina a $300 \mathrm{ppm}+$ cicloheximida a $6,25 \mathrm{ppm}$ foi também eficiente para a análise dos cromossomos de C. stipularia, que são menores que os de $C$. juncea. A Fig. 7 mostra uma metáfase em que se podem distinguir claramente os centrômeros, a constrição secundária no braço curto do cromossomo 1 , bem como o tamanho menor dos cromossomos em relação aos de $C$. juncea. Esta diferença de tamanho já havia sido constatada por Oliveira \& Aguiar-Perecin (1999) e pode ser bem visualizada com o pré-tratamento empregado. Por outro lado, outros prétratamentos utilizando a mesma combinação dos agentes citados mas com maior duração ( 2 horas) ou com maior dose de cicloheximida $(12,5 \mathrm{ppm})$ causaram maior acúmulo de metáfases e prometáfases com cromossomos muito condensados, em que a visualização de sua morfologia fica prejudicada. A Fig. 8 ilustra uma metáfase tratada com 8-hidroxiquinolina a 300ppm + cicloheximida a $6,25 \mathrm{ppm}$, por 2 horas com os cromossomos muito contraídos e morfologia pouco nítida.

Os resultados deste trabalho sugerem que a combinação de 8 -hidroxiquinolina a $300 \mathrm{ppm}$ + cicloheximida a $6,25 \mathrm{ppm}$, durante 1 hora e 30 minutos é bastante adequada para um estudo comparativo de cariótipos de espécies de Crotalaria, sobretudo para a visualização de marcadores cromossômicos evidenciados através de métodos diversos de citogenética (bandamento-C, bandamento com fluorocromos e hibridação in situ fluorescente). A utilização de pré-tratamentos que induzem alto grau de contração dos cromossomos pode ser desejável em casos em que o objetivo seria apenas a contagem do número de cromossomos. A escolha do tipo de pré-tratamento é, portanto, dependente do tamanho dos cromossomos, que pode ser muito variável devido à grande diferença do conteúdo de DNA entre espécies de plantas (Bennett \& Leitch 1995; 1997). O presente trabalho ilustra a situação dos gêneros, Passiflora e Crotalaria, mostrando que os pré-tratamentos de maior eficiência diferem entre os dois grupos. 

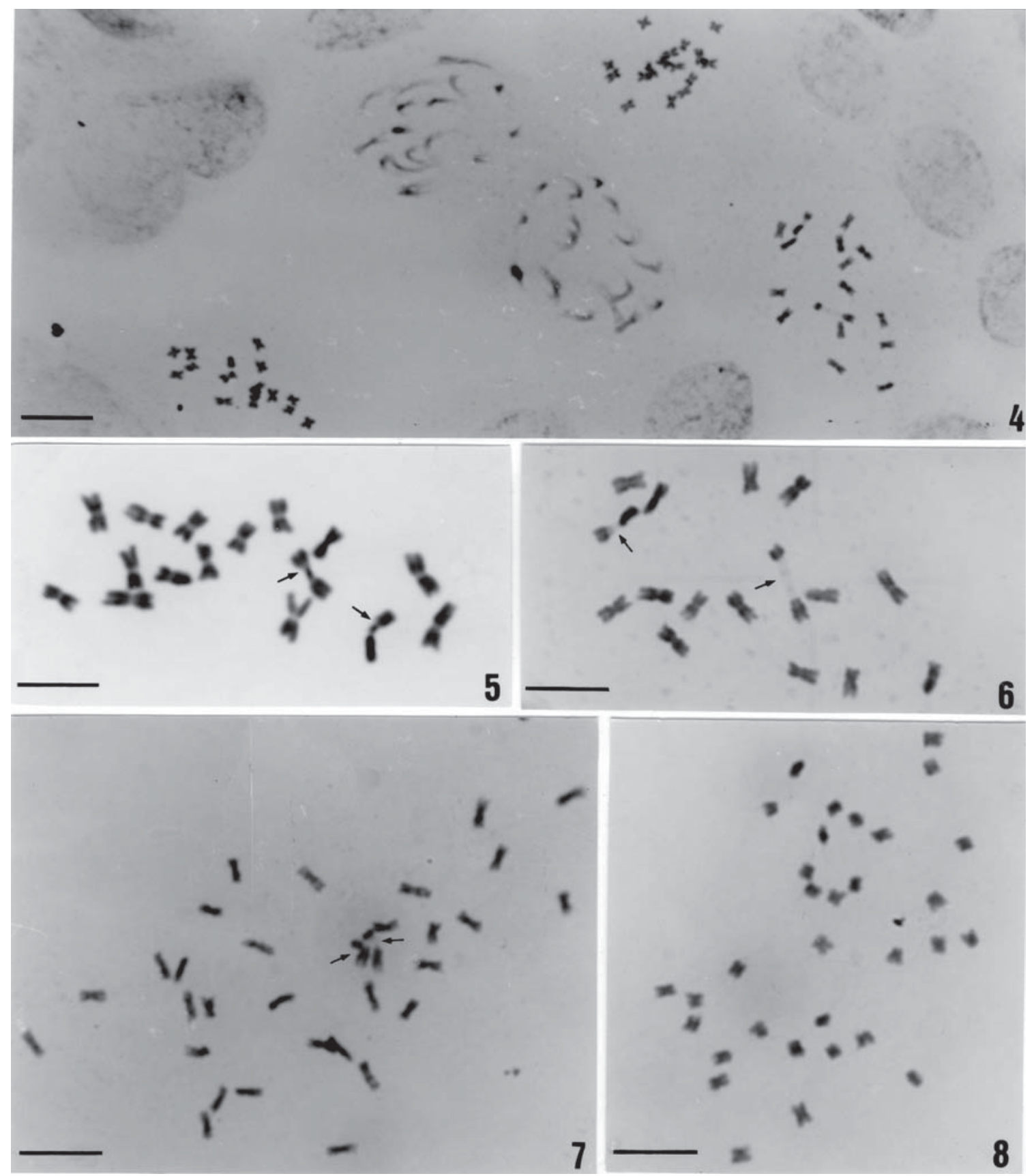

Figuras 4-8. 4. Acúmulo de células metafásicas em meristema radicular de Crotalaria juncea após tratamento com 8-hidroxiquinolina a 300ppm + cicloheximida a 6,25ppm por 1 hora e 30 minutos, e coloração pelo método de Feulgen. 5-6. Respectivamente, metáfase e prometáfase condensada de Crotalaria juncea $(2 \mathrm{n}=16)$, onde se pode observar uma constrição secundária na região proximal do braço curto do cromossomo 1; note-se a constrição muito distendida na prometáfase. 7-8 Metáfases de Crotalaria stipularia, respectivamente tratadas com 8-hidroxiquinolina a 300ppm + cicloheximida a $6,25 \mathrm{ppm}$ durante 1 hora e trinta minutos, e 2 horas. Note-se que a constrição secundária pode ser detectada na Fig. 7. Setas indicam as constrições secundárias. Barras de escala $=5 \mu \mathrm{m}$, exceto em (4) equivalente a $10 \mu \mathrm{m}$. 


\section{Agradecimentos}

Os autores agradecem à FAPESP, pelo apoio financeiro (Proc. 98/01170-5), bem como pelas bolsas de pós-doutorado (Proc. 99/07401-1) e doutorado (Proc. 01/06147-6).

\section{Referências bibliográficas}

Aguiar-Perecin, M. L. R. de \& Vosa, C. 1985. Cbanding in maize. II. Identification of somatic chromosomes. Heredity 54: 37-42.

Barbosa, L.V. \& Vieira, M. L. C. 1997. Meiotic behavior of passion fruit somatic hybrids, Passiflora edulis f. flavicarpa Degener + P. amethystina Mikan. Euphytica 98: 121-127.

Bennett, M. D. \& Leitch, I. J. 1995. Nuclear amounts in Angiosperms. Annals of Botany 76: 113-176.

Bennett, M. D. \& Leitch, I. J. 1997. Nuclear amounts in Angiosperms - 583 new stimates. Annals of Botany 80: 169-196.

Bertão, M. R. \& Aguiar-Perecin, M. L. R. 2002. Maize somatic chromosome preparation: pretreatments and genotypes for obtention of high index of metaphase accumulation. Caryologia 55: 115-119.

De Melo, N. F.; Cervi, A. C. \& Guerra, M. 2001. Karyology and cytotaxonomy of the genus Passiflora L. (Passifloraceae). Plant Systematic and Evolution 226: 69-84.

Dornelas, M. C.; Tavares, F. C. A.; Oliveira, J. C. \& Vieira, M. L. C. 1995. Plant regeneration from protoplast fusion in Passiflora spp. Plant Cell Reports 15: 106-110.

Gupta, R. \& Gupta, P. K. 1978. Karyotypic studies in the genus Crotalaria Linn. Cytologia 43: 357-369.

Killip, E. P. 1938. The American species of Passifloraceae. Publications of the Field Museum of Natural History, Botanical Series 19: 1-613.

Lee, J.; Arumuganathan, K.; Kaeppler, S. M.; Kaeppler, H. F. \& Papa, C. M. 1996. Cell synchronization and isolation of metaphases chromosomes from maize (Zea mays L.) root tips for flow cytometric analysis and sorting. Genome 39: 697-703.
Oliveira, A. L. P. C. \& Aguiar-Perecin, M. L. R. 1999. Karyotype evolution in the genus Crotalaria (Leguminosae). Cytologia 64: 165-174.

Palomino, G. \& Vázquez, R. 1991. Cytogenetic studies in mexican populations of species of Crotalaria (Leguminosae - Papilionoideae). Cytologia 56: 343-351.

Pan, W. H.; Houben, A. \& Schlegel, R. 1993. Highly effective cell synchronization in plant roots by hydroxyurea and amiprophos-metyl or colchicine. Genome 36: 387-390.

Polhill, R. M. 1982. Crotalaria in Africa and Madagascar. A. A. Balkeama, Roterdam.

Raina, S. N. \& Verma, R. C. 1979. Cytogenetics of Crotalaria I. Mitotic complements in twenty species of Crotalaria L. Cytologia 44: 365-375.

Schubert, I.; Dolezel, J.; Houben, A.; Scherthan, H. \& Wanner, G. 1993. Refined examination of plant metaphase chromosome structure at different levels made feasible by new isolation methods. Chromosoma 102: 96-101.

Schwarzacher, T.; Leitch, A. R. \& Heslop-Harrison, J. S. 1994. DNA: DNA in situ hybridization methods for light microscopy. Pp. 127-155. In: N. Harris \& K. J. Oparka (Eds.). Plant Cell Biology: A Practical Approach. Oxford University Press, Oxford.

Silvarolla, M. B. \& Aguiar-Perecin, M. L. R. 1994. Evaluation of chromosome number stability in two sugarcane varieties. Brazilian Journal of Genetics 17: $237-242$.

Snow, N. \& MacDougal, J. M. 1993. New chromosome reports in Passiflora (Passifloraceae). Systematic Botany 18: 261-273.

Storey, W. B. 1950. Chromosome numbers of some species of Passiflora occurring in Hawaii. Pacific Science 4: 37-42.

Tlaskal, J. 1980. Combined cycloheximide and 8hydroxyquinoline pretreatment for study of plant chromosomes. Stain Technology 54: 313-319.

Vanderplank, J. 1996. Passion flowers. 2 ed. The MIT, Cambridge. 